\title{
Reaction of Men to Breast-Implants of Women
}

\author{
Katharina Grundmann ${ }^{1}$, Klaus Hoffmann ${ }^{2}$, Erich Kasten ${ }^{1}$ \\ ${ }^{1}$ Medical School Hamburg, University of Applied Science \& Medical University, Hamburg, Germany \\ ${ }^{2}$ Klinik für Dermatologie und Allergologie der Ruhr Universität, St.-Josef-Hospital, Bochum, Germany
}

Email address:

katgru@yahoo.de (K. Grundmann), k.hoffmann@derma.de (K. Hoffmann), erikasten@aol.com (E. Kasten)

To cite this article:

Katharina Grundmann, Klaus Hoffmann, Erich Kasten. Reaction of Men to Breast-Implants of Women. American Journal of Health Research. Vol. 4, No. 6, 2016, pp. 172-178. doi: 10.11648/j.ajhr.20160406.14

Received: October 2, 2016; Accepted: October 19, 2016; Published: November 9, 2016

\begin{abstract}
Goal of this study was the investigation of men's attitudes toward breast-implants of women. It was examined which opinion men have in regard to artificial filled breasts and whether a preference for big breasts exists, even if the breasts are filled with an implant. A questionnaire was developed, which registered men's opinions concerning breast-implants; it included 12 items on a Likert Scale; mostly the items were bi- or unipolar, others were asked as open text. The inner consistency of the items was Cronbach's Alpha $=0.741$. For the investigation of personality factors the Freiburger Personality Inventory (FPI-R) was used. These questionnaires were published via SosciSurvey, and spread through distribution in social networks. The original sample of $\mathrm{n}=109$ included exclusively male persons between 18-54 years. After use of exclusion criteria, ultimately 81 sets of data were evaluable. Results showed that most men have a preference for big breasts $(\mathrm{p}<0.01)$; but this was not valid for artificial enlarged breasts - here many participants had a neutral attitude and the difference between the number of supporters and opponents was not significant (p-values between 0.11 and 0.92 ). The status of the relationship and the duration of being a single had no relation to the attitudes toward female breast-implants. The hypothesis that men without a partner are more willing to accept breast-implants than men in a relationship rendered only p-values between 0.56 and 0.96 (n.s.). Even the hypothesis "The longer the duration of being single, the higher the acceptance of breast-implants" showed only non-significant $\mathrm{p}$-values between 0.28 and 0.84 . Moreover, the classification of the own attractiveness $(\mathrm{p}=0.297$, n.s.) as well as the score on the extraversion-introversion scale did not affect the attitude toward breast-implants $(\mathrm{p}=0.346$, n.s.). The here presented data show that about half of men nowadays accept artificial enlarged breasts in women. Most distributions had multiple summits, i.e. the participants could be divided in (a) supporters, (b) opponents and (c) a neither/nor group to whom the girl behind the breast is more important. Whether a man is able to accept breast-implants in his girl-friend seems to be a very stable attitude, which is hardly influenced by personality dimensions. Even the duration of a life without a female partner has no significant impact on this attitude.
\end{abstract}

Keywords: Mamma Augmentation, Breast Enlargement, Breast Implants

\section{Introduction}

The term plastic surgery derived from the Greek word plastein (form, create), it includes shape-changing operations reasoned by functional or aesthetic/cosmetic factors or reconstruction of tissue parts after injuries. The most important aim of the Plastic Surgery is to improve visible disturbed body parts. A special form is the aesthetic or cosmetic surgery, which strives for beautifying people. Currently women undergo more of such plastic interventions than men $[9,15]$.

The most performed plastic surgeries are breast operations.
The American Society for Aesthetic Plastic Surgery (ASAPS) counted for the year 2011 about 1.6 million plastic/surgical interventions in the USA. Thereof the mamma-augmentation stands with 329,000 operations in the second place [7]. Breast cancer is one of the indications, but for most of the female patients a breast enlargement is a question of beauty, e.g. if the breasts are too small or not symmetric [5]. Recently published data show that many women interested in breast augmentation actively search the Internet for information. Main motives in a study of Nikolic 
et al. [14] were: desire to feel more feminine $(82.2 \%)$, to be more confident $(75.5 \%)$ and attractive $(73.3 \%)$, to feel less shy with men $(64.4 \%)$, to improve sex life $(46.5 \%)$, teasing history $(42.2 \%)$ and easier to find a partner $(11.1 \%)$ and a job $(2.2 \%)$. The Internet is currently the main source of information on this topic [17]. Even adolescent young people show increasing demand for such surgeries [4, 9, 12]. Especially in the youth, aspects of body dysmorphic disorder need consideration [7].

Main reasons for a mamma augmentation are hereditary small breasts, barely developed breasts or breasts with lost volume (e.g. after an intense weight loss, or age-related hanging breasts). In contrast, several women asked for a surgery of oversized big breasts.

The affected women suffer from an extremely high psychological strain and they often develop the strong wish for normal or immaculate breast. This is understandable, because a narrow association exists between physical beauty and socioeconomic success. Since millenniums of years of human development the female breast is a sign for erotic attractivity. Therefore a mamma-augmentation aims not only to reach a beauty ideal, but also to reduce psychological strain. Already several studies showed the connection between an increase of self-confidence and breast operations. For example in 2011 Bruck, Kleinschmidt and Ottomann [3] investigated the connection between mamma-augmentation and improvements of quality of life (self-confidence, uncertainty, physical appearance and physical discomfort). Here, 58 women were investigated with a standardized questionnaire (FBeK), at first preoperative and six months postoperative after cosmetic submuscular mammaaugmentation with implants. Regarding attractiveness/selfconfidence the study demonstrated a significant improvement after the cosmetic surgery. In addition, the sexual satisfaction increased significant after the operative intervention. The study of Badura [2] dealt with physical changes after breast operations in women. 27 patients, who wished a correction of their mammae, were interviewed. A psychiatricpsychosomatic council judged, whether the operation was reasonable or not. Essential was a clear anatomic malformation of the mammae. Women who suffered from body dysmorphic disorder were excluded. The patients were investigated before and half a year after the operation. All patients indicated a lower self-value before the operation and felt strongly depreciated in their body. Some suffered from depressive symptoms. The surgery leads to significant changes of these variables into a positive direction. In summary a cosmetic mamma-augmentation could contribute to a significant increase of the quality of life for the concerned persons. A test, the BREAST-Q is a patientreported outcome measure that investigates health-related quality of life (HRQOL) and patient satisfaction before and after breast surgery [19].

In 2013 Kalaaji and co-authors [11] investigated characteristics of breast implant patients, including motivations for surgery, depression rate, effect of surgery on daily activity and work activity, and overall psychosocial and cosmetic changes through a self-reported survey. Breast enlargement increased motivation to perform daily activities in their patients. The procedure improved quality of life in both psychosocial and cosmetic aspects. Saariniemi et al. [18] reported that aesthetic breast augmentation results in significant improvement in women's body satisfaction and self-esteem. In their study the level of risk for an eating disorder was also significantly reduced.

Guimaraes and co-authors [8] conducted a study in a plastic surgery clinic in Brazil with 46 patients suffering from hypomastia and 30 patients with breast hypertrophy, who expressed the desire for aesthetic surgery. The patients were assessed preoperatively and 6 months postoperatively using the sexual quotient-scale in the female version (QS-F). The authors found a significant increase in the mean total QS-F score after surgery in both groups $(p<0.001)$. No significant improvement in desire and comfort was reported by patients who underwent breast augmentation and in comfort by patients who underwent breast reduction. Improvement in sexuality after surgery was observed in both groups. Aldermann, Pusic and Murphy found in 2016 that breast implants are effective in improving women's quality of life. The authors reported significant and sustained improvements in satisfaction and psychosocial well-being in women undergoing breast augmentation with implants [1].

\section{Goal of this study}

The above-mentioned studies show that a cosmetic mamma-augmentation could lead to an increase of the quality of life, of self-confidence, and of positive body experiences. But how feels the partner of such women? Until now, no scientific results existed about this topic. What is the reaction of a man, when he experiences that the breasts of his partner are filled with an implant as e.g. silicone? What opinions toward artificial enlarged breasts have men? Which factors influence these attitudes?

The goal of this survey was the interrogation of men toward cosmetic surgery, especially breast enlargement with implants. The following hypotheses were formulated:

$\mathrm{H}(1)$ : "Men have a preference for big breasts."

$\mathrm{H}(2)$ : "Men have negative attitudes toward breast-implants in women."

$\mathrm{H}(3)$ : "Men without partners are more willing to accept breast-implants than men in a partnership."

$\mathrm{H}(3 \mathrm{a})$ : "The longer the duration of being a single, the higher is the acceptance of breast-implants."

$\mathrm{H}(4)$ : "The higher the self-classification of the own attractiveness, the higher is the rejection of artificial breasts on a potential partner."

$\mathrm{H}(5)$ : "Extraverted men reject breast-implants on women more than introverted men."

\section{Methods}

Two questionnaires were used: On the one hand a standardized personality test, the Freiburger Personality Inventory (FPI-R [6]), on the other hand a self-developed questionnaire, which included items about the attitude of men 
toward breast-implants. The self-created questionnaire used scales from -50 up to +50 or from 0 up to 100 . In addition, several personal data were asked (age, existence and duration of a partnership). For the determination of a sufficient sample size, the program "sample sizer" [16] calculated a minimum of $\mathrm{n}=76$ subjects.

The items about the reaction of men toward breastimplants on women were:

a) I perceive big breasts as repulsive ... likable, on a scale:

repulsive $-50-40-30-20-10 \quad 0+10+20+30+40+50$ likable

b) I estimate breast-implants as...

repulsive - likable (scale -50 to +50$)$

disgusting - tasteful (scale -50 to +50 )

unerotic - erotic (scale -50 to +50 )

unattractive - attractive (scale -50 to +50 )

rebarbative - pleasing (scale -50 to +50 )

c) In women with whom I do not have a relationship, I estimate a surgical breast enlargement as acceptable. I do not agree - I agree (scale 0 - 100).

d) The current existence of a partner is irrelevant for my acceptance of breast-implants. I do not agree - I agree (scale 0 - 100).

e) I wish natural breasts on my partner. I do not agree - I agree (scale 0 - 100)..

f) If my partner wishes breast-implants, I stand positively toward this. I do not agree - I agree (scale 0 - 100).

g) I think it would be nice, if my partner already has breast-implants. I do not agree - I agree (scale 0 100).

h) I expect natural beauty from my partner. I do not agree - I agree (scale 0 - 100).

i) I think I am an attractive man. I do not agree - I agree (scale 0 - 100).

To check whether the questionnaires were filled out honestly, some items were repeated in a changed or turned around form. These questions were used to prove the reliability of our test. In subjects who answered these questions honestly, these pairs of question must show a high correlation coefficient. The results showed an acceptable Cronbach's Alpha of 0.74 for all items of the self-developed questionnaire. Thus the inner consistency is in an acceptable range.

The investigation was distributed with the online research portal SosciSurvey. The participants needed about 15-20 minutes to fill out the questionnaires. Hereby, an investigation of a large number of men in a relatively short time was possible. 109 participants filled out the questionnaires, but after filtering the data through the exclusion criteria (not male, improper responses, missing reliability, and too many missing data), only $n=81$ were left.

\section{Results}

The data were analyzed with the program SPSS (Statistical Package for the Social Sciences). Group differences were analyzed with the Mann-Whitney U-Test, correlations were investigated with the Spearman's coefficient. Significance was tested on an alpha-level of $\mathrm{p}<0.05$.

Hypothesis H(1): Men have a preference for big breasts."

For the investigation of the first hypothesis the participants were asked (without the aspect of breast-implants) to answer on a Likert-scale the question "I sense big breasts as..." "repulsive" and "likable". 75.4\% (n=61) men judged big breasts rather as "likeable", $24.7 \% \quad(n=8)$ tended in the direction of "repulsive", and $14.8 \%(n=12)$ chose a scale value of " 0 ", i.e. neither/nor (see Fig. 1). The p-value was 0.0074 , which is highly significant. Hypothesis $\mathrm{H}(1)$ was accepted, i.e. most men have a preference for large breasts of women.

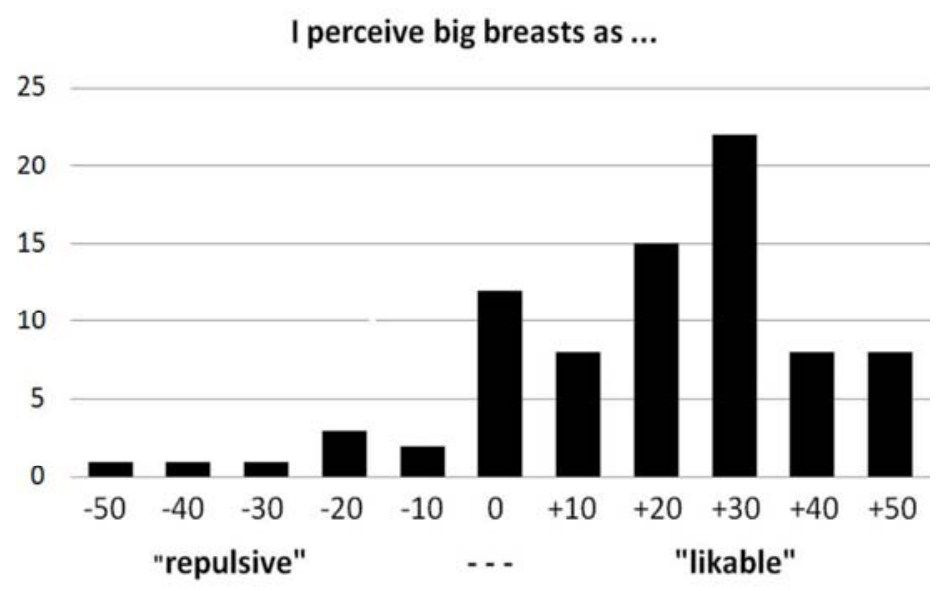

Figure 1. Histogram of men's estimation of the size of female breast on the dimension repulsive $(-50$ to -10$) v s$. likeable $(+10$ to +50$)$. The group of men (24.7\%), who judged big breasts as rather repulsive is much smaller than the group of men who perceived big breasts as likeable (75.4\%), the difference was statistically significant.

Hypothesis $H(2)$ - Men have negative attitudes toward breast-implants in women."
The attitude of men in respect to breast-implants was investigated on five different bipolar scales (1. repulsive - 
likable; 2. disgusting - tasteful; 3. unerotic - erotic; 4. unattractive - attractive; 5. rebarbative - pleasing;)"

(1). For the first dimension, 44.4\% $(n=36)$ of men estimated breast-implants as repulsive (scores -50 to -10 ), $32.1 \%(\mathrm{n}=26)$ were in the central area (score 0$)$, and $23.4 \%$ $(\mathrm{n}=19)$ found implants likeable (scores +10 to +50 ; see Fig. 2 ). Average is $-7.4 \pm 25.0$. For testing whether there is a significant difference between the groups of men who estimated breast-implants as repulsive or likeable, the values below the average of " 0 " were classified in one group and all values above the average were classified in another group. Using the U-Test it was analyzed, whether a significant difference between the both groups exists. If more men admitted a reluctant than an accepting attitude, a clear significant difference must be found. The U-test gave a notsignificant result of $\mathrm{p}=0.11$.

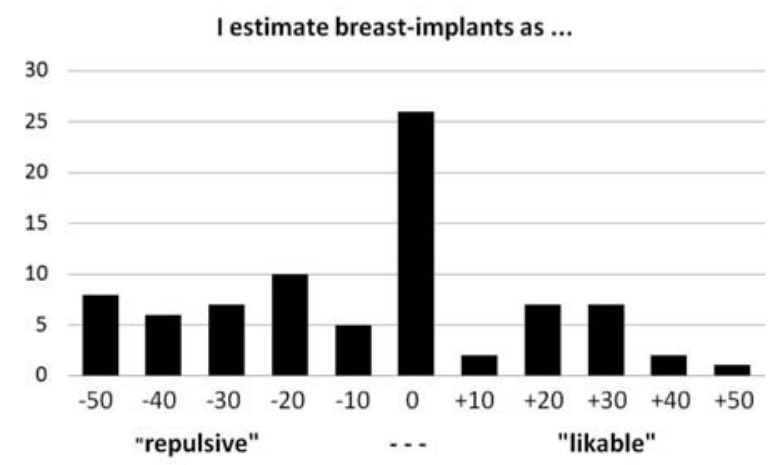

Figure 2. Histogram of men's estimation of female breast-implants on the dimension repulsive vs. likeable. The group of men (44.4\%), who judged implants as rather repulsive is considerable greater than the group of men who judged breast augmentation as likeable (23.4\%), but the difference was not significant in the U-test.

(2). The second item interrogated the opinion of the participants whether they perceived breast-implants as "disgusting" or "tasteful" (see Fig. 3). 29.6\% $(\mathrm{n}=24)$ chose here the " 0 " and decided nor for "disgusting" neither for "tasteful". 44.4\% $(\mathrm{n}=36)$ evaluated breast-implants as "disgusting"; $25.8 \%(\mathrm{~m}=21)$ valued breast-implants in the direction of "tasteful" (see Fig. 3). Average is $-6.4 \pm 23.8$. The U-test gave a not-significant result of $\mathrm{p}=0.21$.

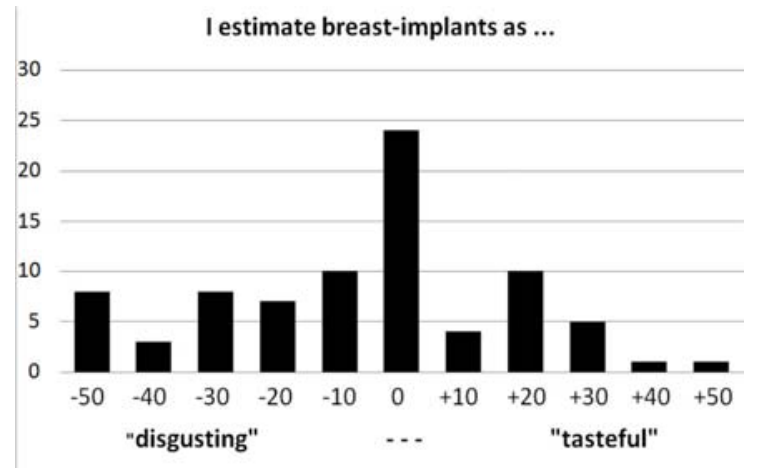

Figure 3. Histogram of men's estimation of female breast-implants on the dimension disgusting vs. tasteful on a -50 to +50 scale. The group of men
(44.4\%), who judged implants as rather disgusting is considerable greater than the group of men who judged breast augmentation as tasteful (25.8\%), but the difference was not significant in the U-test.

(3). Interesting was the result of the item "unerotic" versus "erotic". 43.2\% $(n=35)$ tended to "unerotic", 40.6\% $(n=33)$ tended to "erotic" and $16.0 \%(\mathrm{n}=13)$ answered with a score of " 0 ", which is neither/nor. Average is $-3.6 \pm 29.9$. But the frequency distribution is multimodal, therefore it is difficult to interpret these parameters (see Fig. 4). The U-tests gives a not-significant value of $\mathrm{p}=0.92$.

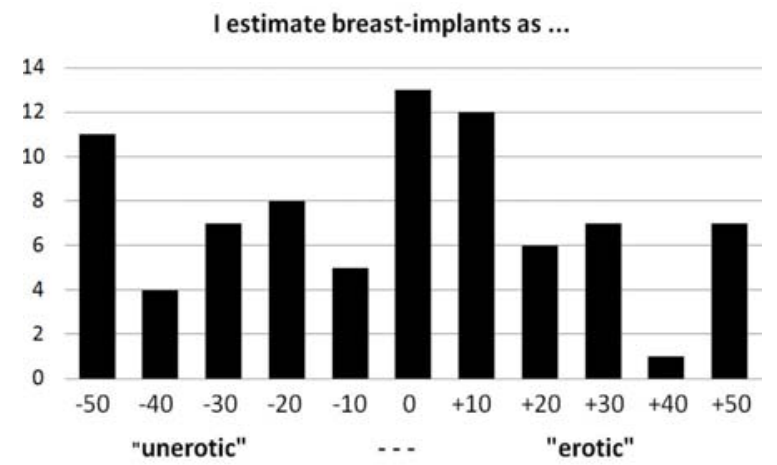

Figure 4. Histogram of men's estimation of female breast-implants on the dimension unerotic vs. erotic. The group of men (43.2\%), who judged implants as rather unerotic is nearly balanced with the group of men who judged breast augmentation as erotic (40.8\%), the difference was statistically not significant.

(4). Comparable with the last item, even several summits had the result of the scale "attractive" versus "unattractive". $44.4 \%(\mathrm{n}=36)$ tended to "unattractive", $38.3 \%(\mathrm{n}=31)$ tended to "attractive" and $17.3 \%(\mathrm{n}=14)$ answered with a score of " 0 ", which is neither/nor. Average is $-4.2 \pm 29.4$. But the frequency distribution shows multiple summits, therefore it is difficult to interpret these parameters (see Fig. 5). The U-tests gives a not-significant value of $\mathrm{p}=0.67$.

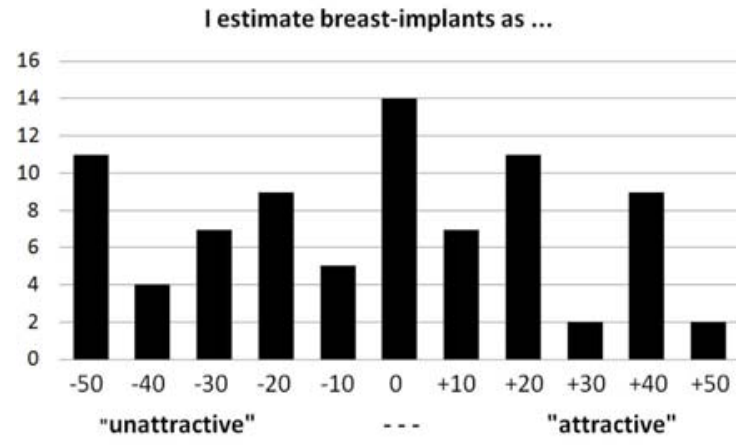

Figure 5. Histogram of men's estimation of female breast-implants on the dimension unattractive vs. attractive. $43,2 \%(n=35)$ tend to inerotic," 40,6\% $(n=33)$ to erotic."

(5). For the question whether men judged breast-implants as "rebarbative" or "pleasing", the following results emerged: $32.1 \% \quad(\mathrm{n}=26)$ chose scale value 0 (neither/nor). $30.8 \%$ $(\mathrm{n}=25)$ experienced breast-implants rather as "rebarbative" 
and $37.0 \%(\mathrm{n}=30)$ as rather "pleasing" (see Fig. 6). Average is $0 \pm 25.2$. The U-test gives a p-value of 0.59 , which is far from any significance.

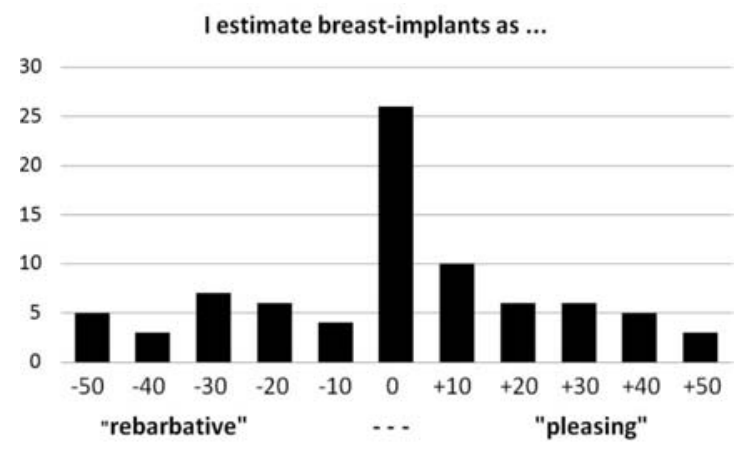

Figure 6. Histogram of men's estimation of female breast-implants on the dimension rebarbative vs. pleasing. The group of men (30.8\%), who judged implants as rather rebarbative is nearly balanced with the group of men who judged breast augmentation as pleasing (37.0\%), the difference was statistically not significant.

In summery the hypothesis $\mathrm{H}(2)$ "Men have a negative attitude toward breast-implants" is not accepted and has to be discarded. In none of the items, a significant difference was achieved. The group of men who estimated breast-implants positive is nearly as large as the group of men who judged implants as negative.

Hypothesis H(3): Men without partners are more willing to accept breast-implants than men in a partnership."

The averages of both groups, i.e. men with partners versus men without a female partner, were compared in regard to their attitude toward breast-implants with the U-Test. The attitude toward breast-implants was covered with the above described 5 items ("I sense breast-implants as..."). The results show no significant differences between the two groups, i.e. men without a partner are not more willing to accept breastimplants than men within a relationship (see Table 1).

Table 1. Averages on the scale -50 to +50 , standard deviations, and significance in the U-Test for the difference whether men with/without a female partner are more willing to accept breast-implants of women.

\begin{tabular}{llll}
\hline I sense breast-implants as... & $\begin{array}{l}\text { Men with female partner } \\
(\mathbf{n = 7 1 )}\end{array}$ & $\begin{array}{l}\text { Men without female partner } \\
(\mathbf{n = 3 8 )}\end{array}$ & Significance in U-Test \\
\hline repulsive-likeable & $-7.2 \pm 24.3$ & $-7.6 \pm 26.6$ & $\mathrm{p}=0.56 \mathrm{n} . \mathrm{s}$. \\
disgusting-tasteful & $-8.8 \pm 25.2$ & $-3.7 \pm 22.2$ & $\mathrm{p}=0.56 \mathrm{n} . \mathrm{s}$. \\
unerotic-erotic & $-5.3 \pm 27.5$ & $-1.6 \pm 32.8$ & $\mathrm{p}=0.96 \mathrm{n} . \mathrm{s}$. \\
unattractive-attractive & $-5.1 \pm 27.8$ & $-3.3 \pm 31.5$ & $\mathrm{p}=0.85 \mathrm{n} . \mathrm{s}$. \\
rebarbative-pleasing & $-2.1 \pm 2.4 .4$ & $+2.6 \pm 26.2$ & $\mathrm{p}=0.82 \mathrm{n} . \mathrm{s}$. \\
\hline
\end{tabular}

Hypothesis H(3a): The longer the duration of being a single, the higher is the acceptance of breast-implants."

Men without partners $(46.9 \%, \mathrm{n}=38)$ were divided into four categories: (a) men without a partner since less than one year $(28.9 \%, \mathrm{n}=11),(\mathrm{b})$ since one up to two years $(52.6 \%$, $\mathrm{n}=20)$, (c) since three to four years $(10,5 \%, \mathrm{n}=4)$ and $(d)$ since more than four years $(7,9 \%, n=3)$. Here again the results of the respective five items toward the attitude of breast-implants were used.

Table 2 shows an overview of the averages of the responses of single men. As said above, on this -50 to +50 scales the value 0 illustrates the neutral response point. Values below 0 tend to the negative area of the item and values above 0 tend in to the positive area of the respective item.

Table 2. Duration of being single and attitude to female breast-implants in comparison to men with a female partner.

\begin{tabular}{lllll}
\hline I sense breast-implants as... & Single $<$ 1 year $(\mathbf{n}=\mathbf{1 1})$ & Single 1-2 years $(\mathbf{n}=\mathbf{2 0})$ & Single 3-4 years $(\mathbf{n}=\mathbf{4})$ & Single $>$ 4 years $(\mathbf{n}=\mathbf{3})$ \\
\hline repulsive-likeable & -14 & -1 & -10 & -7 \\
distgusting-tasteful & -1 & -2 & -10 & -17 \\
unerotic-erotic & -1 & 0 & +10 & -10 \\
unattractive-attractive & +2 & -1 & -3 & -7 \\
rebarative-pleasing & +8 & +4 & -30 & -13 \\
\hline
\end{tabular}

Using the Kruskal-Wallis test, it was calculated whether the central tendencies differ significantly from each other. One can see in table 3 that all p-values are far from the limit of $p<0.05$. Therefore the hypothesis $\mathrm{H}(3)$ was rejected. The duration of being single does not stay in any connection with the attitude toward breast-implants. One cannot say that the longer the duration of being a single, the higher the acceptance of breast-implants.

Table 3. Results of Chi' ${ }^{2}$-test for the hypothesis The longer the duration of being a single, the higher is the acceptance of breast-implants."

\begin{tabular}{llllll} 
& repulsive-likeable & disgusting-tasteful & unerotic-erotic & unattractive-attractive & rebarbative-pleasing \\
\hline $\mathrm{Chi}^{2}$ & 3.80 & 0.84 & 2.88 & 2.90 & 1.41 \\
Asymp. Sig. & $\mathrm{p}=0.28$ & $\mathrm{p}=0.84$ & $\mathrm{p}=0.41$ & $\mathrm{p}=0.41$ & $\mathrm{p}=0.70$ \\
\hline
\end{tabular}

Hypothesis H(4): The higher the self-classification of the own attractiveness, the higher is the rejection of artificial breasts on a potential partner."

This hypothesis was checked with calculation of the correlation coefficient Spearman's Rho. The participants were asked to indicate a value between 0 ("disagree absolutely") and 100 ("agree very much") in all items. The Spearman's correlation coefficient was $\mathrm{R}=0.117$, which 
means only a minor connection. The level of significance is $\mathrm{p}=0.297$, i.e. not-significant. Therefore the hypothesis was rejected and it was not proved that the self-classification of the own attractiveness stands in relation to the acceptance or rejection of artificial breasts of the partner.

Hypothesis H(5): Extraverted men reject breast-implants of women more than introverted men."

The idea behind this hypothesis is that extraverted men have easier contact to unknown people and have no problems to talk with new women. Introverted men are shy and have bigger problems to date with a woman. The last hypothesis was tested also with the Spearman's Rho correlation coefficient. Here, the sum of all items with regard to the personality dimension Extraversion/Introversion from the Freiburger Personality Inventory (FPI-R, [6]) was correlated with the sum of the 5 items regarding the attitude toward breast-implants ("I sense breast-implants as..."). The correlation coefficient was $\mathrm{R}=-0.106$, which means a weak to moderate negative connection. The significance level of $\mathrm{p}=0.346$ was not significant, i.e. extraverted men have no higher rejecting attitude toward breast-implants on women compared with introverted men.

\section{Discussion}

This study revealed some important results about male attitudes toward breast-implants of women. After application of the exclusion criteria the data of 81 men were analyzed, which was higher than the calculated minimum of sample size.

This first hypothesis "Men have a preference for big breasts" was accepted: More than 75\% of the interrogated men found big breasts attractive. The reasons are multilayered. The female breast receives much attention from men, more than many other body parts. From zoological point of view the female breast has a motherly-nourishing function. In monkeys and apes females have flat breasts, which only swells up during the breast-feeding, but even in this condition the breast has not the size of female humans. The anatomy of human breast shows that it consists mainly of fat tissue and only a small part is responsible for the milk production. So its function has to be more extensive than only motherly-nourishing. The female breast sends sexual signals, which should be detected by men. But the female flat-breasted primates had a pendant to the rounding of the breasts of human woman - her buttocks. Because female primates walk on all limbs, they send sexual signals with their buttocks, which swell up in phases of sexual willingness, i.e. these parts of the body are visible stimuli to excite the male animal. It was supposed that the buttocks have the same function in the primates as the breasts of a human woman. The zoologist Desmond Morris [13] wrote about the female body that, when a woman is talking to a man face to face, the signals from her buttocks are not visible. Harris believes that the breasts are two imitated buttocks to replace the original sexual signal, without turning her back to the partner (Morris 2004, p. 151). Breasts allow the assignment of a gender from a great distance and their appearance has a considerable subconscious effect, increasing the sexual excitement $[13,20]$. From this point of view, the acceptance of the hypothesis $\mathrm{H}(1)$ is reasoned by the human evolution, big breast may be a symbol for the willingness for mating.

The second hypothesis "Men have a negative attitude toward breast-implants of women" was rejected. The data revealed no significant difference of the number of men who responded into the direction of repulsive, disgusting, unerotic, unattractive, rebarbative and, on the other hand, the men who estimated breast-implants as likable, tasteful, erotic, attractive, and pleasing. This means, it was not proved that men generally consider breast-implants as negative. For most of the items there were about as many men who estimated implants as positive as there were men with a negative attitude. It is noticeable that always a considerable number of participants emphasized the neither/nor neutrality.

A possible explanation could be that for most men the form and the strength of a female breast are more important than the question whether the breast is natural or filled with an implant. From an anthropological point of view, the breasts of a woman stand for reproductive capacities, as well as for sensuality and feminine aspects. Especially when love emerges in a man, it is more important for the first optic impression of a woman that visible breast serve as an instinct-based sexual stimulus. A restriction is that the size of the breast must suit to the whole image of a woman: large breasts could contradict a sporty and well-trained body. The size of the breast must stand in a natural proportion with the remnant of the body.

The hypothesis (3) "Men without a partner are more willing to accept breast-implants than men in a relationship" was rejected. There was no significant difference between men with and without a female partner regarding their attitude toward breast-implants. An interpretation would be that size or forms of breast are more important than the fact whether they are natural or cosmetically optimized. This main attitude of men seems to be stabile, independent whether he has a partner or not. The relationship status does not influence the attitude toward breast implant.

The (3a) hypothesis: "The longer the duration of being a single, the higher is the acceptance of breast-implants" was as well rejected. The duration of being a single stood not in a connection with the attitude toward breast-implants.

The (4) hypothesis "The higher the self-classification of the own attractiveness, the higher is the rejection of artificial breasts on a potential partner" was rejected. The selfclassification of the own attractiveness has had no influence on the attitude to breast-implants. A possible explanation may be that exactly the opposite can be the case: If a man considers himself as attractive, appealing and desirable, he may expect the same from his female partner. This may lead to an optimized body shape with enlarged breasts.

The last hypothesis: "Extraverted men reject breastimplants on women more than introverted men" was as well rejected. This result states that the personality-dimension 
extraversion/introversion had no influence on the attitude regarding breast-implants. How sociable, impulsive, adventurous or extraverted a man is, has apparently no influence on whether he has an accepting or rejecting attitude toward breast-implants.

\section{Conclusions}

The current literature shows that the size of breast has not only an influence on men, but also on the self-confidence of women. In the last century beauty surgery was judged as embarrassing and was often shameful occupied. The here presented data show that nowadays up to half of men accept artificial enlarged breasts in women. It must be recognized that most distributions had multiple summits, i.e. the participants could be divided in (a) supporters, (b) opponents and (c) a neither/nor group to whom the character of the girl behind the breast is more important. Whether a man is able to accept breast-implants in his girl-friend seems to be a very stable attitude, which is hardly influenced by personality dimensions. Even the duration of a life without a female partner has no significant impact on this attitude. Either you like it - or not.

\section{References}

[1] Alderman, A., Pusic, A. \& Murphy, D. K. (2016): Prospective Analysis of Primary Breast Augmentation on Body Image Using the BREAST-Q: Results from a Nationwide Study. Plast Reconstr Surg. 137 (6): 954e-60e. doi: 10.1097/PRS.0000000000002183.

[2] Badura H. O. (1983): Zum somatopsychischen Einfluß plastischer Brustoperationen. [Psychosomatic effect of mammoplasty]. In: Psychotherapie, Psychosomatik, Medizinische Psychologie. 1983, 33 (5): 179-182.

[3] Bruck J. C. Kleinschmidt, A. \& Ottomann, C. (2011): Gesteigertes Selbstvertrauen und vermindertes körperlichsexuelles Missempfinden nach subpektoraler Breast augmentation [Increased Self-Confidence and Decreased Sexual Discomfort after Subpectoral Mammaplasty]. J Handchir Mikrochir plast Chir. 43 (2): 112-118. DOI: $10.1055 / \mathrm{s}-0030-1265164$.

[4] Crerand, C. E. \& Magee, L. (2013): Cosmetic and reconstructive breast surgery in adolescents: psychological, ethical, and legal considerations. Semin Plast Surg. 27 (1): 7278. doi: $10.1055 / \mathrm{s}-0033-1343999$.

[5] Dini, G. M., Gozzano, R., Ferreira, R. B., Faria, M., Farinazzo, M. \& Ferreira, L. M. (2014): Mirror, mirror on the wall, which breast is bigger of them all? Plast Reconstr Surg Glob Open. 6; 2 (2): e105. doi:

$10.1097 /$ GOX.0000000000000037.

[6] Fahrenberg, J., Hampel, R. \& Selg, H. (1984): Freiburger Persönlichkeitsinventar. Göttingen: Hogrefe.

[7] Figueroa-Haas, C. (2009): Psychological issues associated with breast augmentation. Issues Ment Health Nurs. 30 (6):
377-82. doi: 10.1080/01612840802488657.

[8] Guimaraes, P. A., Resende, V. C., Sabino Neto, M., Seito, C. L., de Brito, M. J., Abla, L. E., Veiga, D. F. \& Ferreira, L. M. (2015): Sexuality in aesthetic breast surgery. Aesthetic Plast Surg. 39 (6): 993-9. doi: 10.1007/s00266-015-0574-9.

[9] Horch, R. E. \& Kneser, U. (2012): Plastische Chirurgie. In. Siewert \& Stein (Eds.): Chirurgie. Heidelberg: Springer.

[10] Jordan, S. W. \& Corcoran, J. (2013): Considerations in breast augmentation in the adolescent patient. Semin Plast Surg. 27 (1): 67-71. doi: 10.1055/s-0033-1343998.

[11] Kalaaji, A., Bjertness, C. B., Nordahl, C. \& Olafsen, K. (2013): Survey of breast implant patients: characteristics, depression rate, and quality of life. Aesthet Surg J. 33 (2): 252-7. doi: 10.1177/1090820X12473106.

[12] Larson, K. \& Gosain, A. K. (2012): Cosmetic surgery in the adolescent patient. Plast Reconstr Surg. 129 (1): 135e-141e. doi: 10.1097/PRS.0b013e3182362bb8.

[13] Morris, D. (2004): Die nackte Eva [The naked Eva]. München: Wilhelm Heyne Verlag.

[14] Nikolic, J., Janjic, Z., Marinkovic, M. Petrovic, J. \& Bozic, T. (2013): Psychosocial characteristics and motivational factors in woman seeking cosmetic breast augmentation surgery. Vojnosanit Pregl. 70 (10): 940-946.

[15] Reichenberger, M. A., Biedermann, N. \& Germann, G. (2011): Ästhetische Brustvergrößerung [Aesthetic breast augmentation]. Der Chirurg. 82: 782. DOI: $10.1007 / \mathrm{s} 00104-$ 011-2108-6.

[16] Reinboth, C. (2008): SampleSizer: Tool zur Bestimmung des optimalen Stichprobenumfangs. In: Statistikberatung. URL: http://statistikberatung.blogspot.de/2008/03/samplesizerkostenloses-tool-zur.html (abgerufen am 13. August 2014).

[17] Palma, A. F., Zuk, G., Raptis, D. A., Franck, S., Eylert, G., Frueh, F. S., Guggenheim, M. \& Shafighi, M. (2016): Quality of information for women seeking breast augmentation in the Internet. J Plast Surg Hand Surg. 50 (5): 262-71. doi: 10.3109/2000656X.2016.1154469.

[18] Saariniemi, K. M., Helle, H. M., Salmi, A. M., Peltoniemi, H. H., Charpentier, P. \& Kuokkanen, H. O. (2012): The effects of aesthetic breast augmentation on quality of life, psychological distress, and eating disorder symptoms: a prospective study. Aesthetic Plast Surg. 36 (5): 1090-5. doi: 10.1007/s00266012-9917-y.

[19] Saiga, M., Taira, N., Kimata, Y., Watanabe, S., Mukai, Y., Shimozuma, K., Mizoo, T., Nogami, T., Iwamoto, T., Motoki, T., Shien, T. Matsuoka, J. \& Doihara, H. (2016): Development of a Japanese version of the BREAST-Q and the traditional psychometric test of the mastectomy module for the assessment of HRQOL and patient satisfaction following breast surgery. Breast Cancer. DOI 10.1007/s12282-016-07036.

[20] Schipperges; I. \& und Simon, V. (2014): Bin ich nicht schön? Schönheitsideale der Kulturen. [Am I beauty? Ideals of attractiveness of cultures]. In: Süddeutsche Zeitung. Stand 2010.

URL:

http://www.sueddeutsche.de/leben/schoenheitsideale-derkulturen-bin-ich-nicht-schoen-1.204145 (10. Juni 2014). 